\title{
Comparison of the Pathological Picture of Experimental Diabetic Nephropathy in Rats at Early (1 month) and Late (8 months) Stages
}

\author{
A. Yu. Zharikov, PhD, ScD ${ }^{1,2}$; S. O. Filinova ${ }^{1 *}$; O. N. Mazko, $\mathrm{PhD}^{1}$; \\ O. G. Makarova, $\mathrm{PhD}^{1}$; Yu. V. Korenovsky, $\mathrm{PhD}^{1}$; A. V. Lepilov, $\mathrm{PhD}, \mathrm{ScD}^{1}$; \\ I. P. Bobrov, $\mathrm{PhD}, \mathrm{ScD}^{1}$; O. V. Azarova, $\mathrm{PhD}, \mathrm{ScD}^{1}$ \\ ${ }^{1}$ Altai State Medical University, Barnaul, the Russian Federation \\ ${ }^{2}$ Scientific-Research Institute of Physiology and Basic Medicine, Novosibirsk, the Russian Federation
}

\begin{abstract}
The research objective was to investigate the pathological picture of diabetic nephropathy in the 8-month streptozotocin (STZ)-induced diabetes mellitus and compare it with the previously obtained picture of diabetic nephropathy in the 1-month STZinduced diabetes mellitus (DM).

Materials and methods: Experiments were conducted on 15 male Wistar rats aged 2-3 months and weighing 250-280 g. To induce DM, the animals were injected intraperitoneally $1 \mathrm{ml}$ of STZ solution in the citrate buffer at a dose of $65 \mathrm{mg} / \mathrm{kg}$. In accordance with modern ideas about the peculiarities of DM modeling using STZ for more selective modeling of type 2 DM, the rats were previously injected with an intraperitoneal solution of cytoflavin based on a nicotinamide dose of $115 \mathrm{mg} / \mathrm{kg}$. After 8 months of the experiment, the concentration of glucose, protein, and creatinine was determined in urine. The animals were euthanized under ethereal anesthesia and both kidneys were extracted, cleaned and washed with a physiological solution. In the renal tissues of animals, we determined the concentration of thiobarbituric acid reactive products, total pro-oxidant activity, total antioxidant activity, activity of antioxidant enzymes (catalase, superoxide dismutase, and glutathione peroxidase). With the help of a morphometric method of research, the area of renal glomeruli and the area of capillary lumens were measured, and after a special computer processing of digital photos, the total area of the vascular bed in the glomerulus and the area of mesangium in the renal glomerulus were assessed.

Results: Diabetic nephropathy in the 8-month STZ-induced DM was more pronounced than with the 1-month STZ-induced DM. The revealed biochemical and morphological signs of the 8-month STZ-induced DM indicate the irreversible nature of its course and the impossibility of its pharmacological correction.(International Journal of Biomedicine. 2019;9(4):345-349.)
\end{abstract}

Key Words: diabetes mellitus $\bullet$ streptozotocin $\bullet$ diabetic nephropathy

\section{Introduction}

The problem of finding ways to effectively treat diabetes mellitus (DM) and its complications remains one of the main issues of modern medicine. ${ }^{(1)}$ Among the most frequent and dangerous complications of this disease, diabetic nephropathy (DN) takes one of the leading positions. ${ }^{(2)}$

According to modern ideas, DN is a disease caused by a set of pathological processes initiated by hyperglycemia and

*Corresponding author: Svetlana O. Filinova. Altai State Medical University, Barnaul, the Russian Federation. E-mail: filinova.87@inbox.ru hyperglucosuria. ${ }^{(3)}$ It has been established that aldosteroneassociated mechanisms, free-radical oxidation (FRO) processes, and lipid metabolism disorders can make a significant contribution to kidney damage. ${ }^{(3)}$ In addition, advanced views on the pathogenesis of DN increasingly focus on possible pathological modification of proteomic nephroprotection mechanisms in DM, operating in the norm..$^{(4)}$ For example, endogenous dipeptide carnosine ( $\beta$-alanyl-L-histidine) is known to play a protective role in renal pathologies, including $\mathrm{DN}^{(5,6)}$ It is possible that a certain modification of its structure or function against the background of diabetes deprives it of nephroprotective properties, which contributes to the development of pathology. 
All of the above allows researchers to identify targets in the pathogenesis of DN for the development of new approaches to targeted correction of the disease. At the same time, an important question remains unresolved: At what stages of DN are effective medicinal corrections possible? Earlier, having conducted a study, we described the biochemical and pathological picture of DN on the background of experimental streptozotocin $(S T Z)$-induced DM in rats for a period of 1 month..$^{(7,8)}$ The outcome of the 1-month STZ-induced DM was that hyperglucosuria and proteinuria developed, that FRO process was activated and that a number of characteristic morphological signs of glomerulus damage had emerged. ${ }^{(7,8)}$ However, it is widely believed that persistent nephropathy develops only after 8 months of DM modeling. In this regard, the research objective was to investigate the pathological picture of DN in the 8-month STZ-induced DM and compare it with the previously obtained picture of $\mathrm{DN}$ in the 1-month STZ-induced DM.

\section{Materials and Methods}

Experiments were conducted on 15 male Wistar rats aged 2-3 months and weighing 250-280 g. Animals were grown in the Department of Animal and Human Genetics of the Federal Research Center "Institute of Cytology and Genetics" of the Siberian branch of the Russian Academy of Sciences (Novosibirsk). The work with animals was carried out in accordance with the principles of humanism laid down in the directives of the European Community (86/609/EEC) and the Declaration of Helsinki, in accordance with the "Animal experimentation legislations".

To induce DM, the animals were injected intraperitoneally $1 \mathrm{ml}$ of STZ solution in the citrate buffer at a dose of $65 \mathrm{mg} / \mathrm{kg}$. In accordance with modern ideas about the peculiarities of DM modeling using STZ for more selective modeling of type $2 \mathrm{DM}$, the rats were previously injected with an intraperitoneal solution of cytoflavin based on a nicotinamide dose of $115 \mathrm{mg} / \mathrm{kg} .{ }^{(9)} \mathrm{After}$ STZ administration, the animals were in a common metabolic cell on a standard laboratory diet, in conditions of free access to fluids. Two weeks before the end of the experiment, the rats were distributed to individual cells adapted for urine collection in order to assess the biochemical markers of kidney function on the last day of the experiment.

After 8 months of the experiment, the animals were euthanized under ethereal anesthesia and both kidneys were extracted, cleaned and washed with a physiological solution, one of which was used to determine the activity of FRO process in the renal tissue, and the other one for morphological research.

In urine, the concentration of glucose, protein, and creatinine was determined on the automatic biochemical analyzer DIRUICS-T240. Glucose concentration was determined by the method of enzymatic oxidation of glucose in the presence of glucose oxidase, which is based on the measurement of the optical density of the colored quinone imine compound. To determine protein concentration, a biuretic method was used, which is based on the formation of a blue-violet color complex with copper ions, the optical density of which is directly proportional to the protein concentration. Creatinine concentration was determined by a kinetic method without deproteinization based on the Jaffe reaction with formation of a red-orange colored complex.

The activity of the FRO processes was estimated by a combination of pro-oxidant and antioxidant indicators. ${ }^{(10)}$ Indicators of oxidant status were determined in the homogenate of the cortical substance of the kidneys. The total concentration ratio of all pro-oxidants and free-radical metabolites, and total pro-oxidant activity (TPA), were assessed by the intensity of coloring of the fluorescent complex formed by the interaction of Tween- 80 peroxidation products and thiobarbituric acid. Additionally, the concentration of malondialdehyde (MDA) and other thiobarbituric fatty acid reactive products (TBARP) was determined in tissues.

The activity of the antioxidant system was investigated in the homogenate of the cortical substance of the kidneys. Total antioxidant activity (TAA) was assessed as an integrative activity indicator of all enzymatic and nonenzymatic factors of neutralization of free radicals by degree of oppression of $\mathrm{Fe}^{2+} /$ Tween- 80 ascorbate-dependent oxidation by tissue homogenate. To assess the antioxidant status of cells, the activity of antioxidant enzymes was determined: catalase (CAT), superoxide dismutase (SOD), and glutathione peroxidase (GPx). The CAT activity was determined by suppressing sodium molybdate with the oxidation enzyme of hydrogen peroxide: hydrogen peroxide oxidizes sodium molybdate to form colored products; the decomposition of hydrogen peroxide under the action of catalase reduces the degree of coloring of the samples. The calculation was carried out relative to the control sample. The SOD activity was assessed at the content of nitroformazan in the sample, which is a colored product of nitrotetrazolium oxidation by superoxide radicals formed by interaction of phenazinmetasulfate and nicotinamidinucleotide (NADN). To determine the glutathione peroxidase (GPx) activity, the concentration of reduced glutathione was measured in a colored reaction with Ellman's reagent.

For morphological studies, the material was fixed in $10 \%$ neutral formalin solution. The material was dehydrated in isopropyl alcohol using a carousel-type dehydration machine TISSUETEK VIPTM6 (Sakkura, Japan), and then poured into paraffin using the paraffin filling station TISSUE-TEK TEC 5(Sakkura, Japan). Histological sections 2-4 $\mu \mathrm{m}$ thick were obtained using a semi-automatic rotary microtome Accu-Cut SRM (Sakkura, Japan). In each preparation, 20-25 glomeruli were evaluated. For testing, 3-4 preparations of each kidney were taken from each animal. All preparations were photographed with a digital camera with various zoom, which allowed fully visualizing at what level the glomeruli were located. We investigated glomeruli, which were located on one and the same level and approached the shape of a circle; elongated or deformed glomeruli were not included. We also did not investigate glomeruli that were cut superficially and were too small to avoid the impact of the cut level. The sections were stained with H\&E in a TISSUE-TEK Prisma machine for micro-section automatic staining (Sakkura, Japan). Histochemical staining on neutral glycosaminoglycans was also carried out by Schiff-reagent, according to McManus, 
and on acidic glycosaminoglycans with a $1 \%$ alcian blue solution on $3 \%$ acetic acid, according to Steedman ( $\mathrm{pH} 2.5)$. Preparations were placed under a coating film, TISSUE-TEK Film, in a device for the automatic enclosure of micro-sections (Sakkura, Japan). Morphometric studies were performed using a specially created computer image analysis system consisting of a Leica DME microscope(Germany), a Leica EC3 digital camera (Leica Microsystems AG, Germany), a personal computer, and Video Test Morphology 5.2 software. With the help of a morphometric method of research, the area of renal glomeruli and the area of capillary lumens were measured, and after a special computer processing of digital photos, the total area of the vascular bed in the glomerulus and the area of mesangium in the renal glomerulus were assessed.

Statistical analysis was performed using StatSoft Statistica v12.0. The results of biochemical studies are presented as the median (Me) and interquartile range (IQR; 25 th to 75 th percentiles). The results of morphometric studies are presented as the mean (M) and standard error of the mean (SEM). Statistical comparisons between groups were performed using the Mann-Whitney U-test. A probability value of $P<0.05$ was considered statistically significant.

\section{Results}

Experiments showed that after 8 months of STZ-induced DM, there was a pronounced glycosuria (Table 1). Glucose concentration in urine exceeded the level of 1 month by 2.7 times $(P=0.0000)$, and glucose excretion was 1.7 times higher $(P=0.0000)$. The levels of diuresis, creatinine excretion and protein concentration in urine after 1 month and 8 months of STZinduced DM did not differ significantly. At the same time, the level of protein excretion at 8 months was significantly lower, by 2.1 times, compared to the indicator of 1 month $(P=0.002)$.

Against this background, the study of the activity of FRO process in the kidneys of rats with 8-month DM showed that levels of TPA decreased by 2.5 times $(P<0.0001)$, TAA by 4.1 times $(P<0.0001)$, and SOD activity by 2 times $(P=0.014)$, in comparison with 1-month DM. TBARP concentration, GPx and CAT activities did not differ significantly between time groups (Table 2).

The results of a morphological study, presented in Table 3, showed that after 8 months of STZ-induced DM, the kidney glomeruli of the experimental animals were enlarged, surpassing the indicator of healthy animals by 1.3 times $(P=0.0003)$, and were almost no different from the indicator in the group of the 1-month STZ-induced DM.
In addition, there was a significant expansion of the intercapillary space due to the accumulation of Schiff-positive mesangium and connective tissue (Fig. 1a). The mesangium area in glomeruli exceeded the level of healthy rats by 1.5 times $(P=0.001)$ on average, which also generally corresponded to the indicator recorded after 1 month of STZ-induced DM. At the same time, the total area of vessels in the glomerulus (Fig. 1b) was 1.7 times less than the level in the 1-month STZ-induced diabetic rats $(P=0.0000)$ and 2.7 times less than the level of healthy rats $(P=0.0000)$. The area of capillary lumens in the glomerulus of the 8-month STZ-induced diabetic rats (Fig. 1c) was inferior to the level of the 1-month STZinduced diabetic rats by 1.9 times $(P=0.0000)$, which, in turn, did not differ from intact rats. The basal membranes of the glomeruli capillaries were significantly thickened, the capillary lumen was narrowed. The capsule of the kidney glomeruli looked thickened. There was no capsule cavity in most tubules. Glomeruli capillaries were full-blooded. In the kidney interstitium, there were foci of nephrosclerosis and lymphoplasmacytic infiltration.

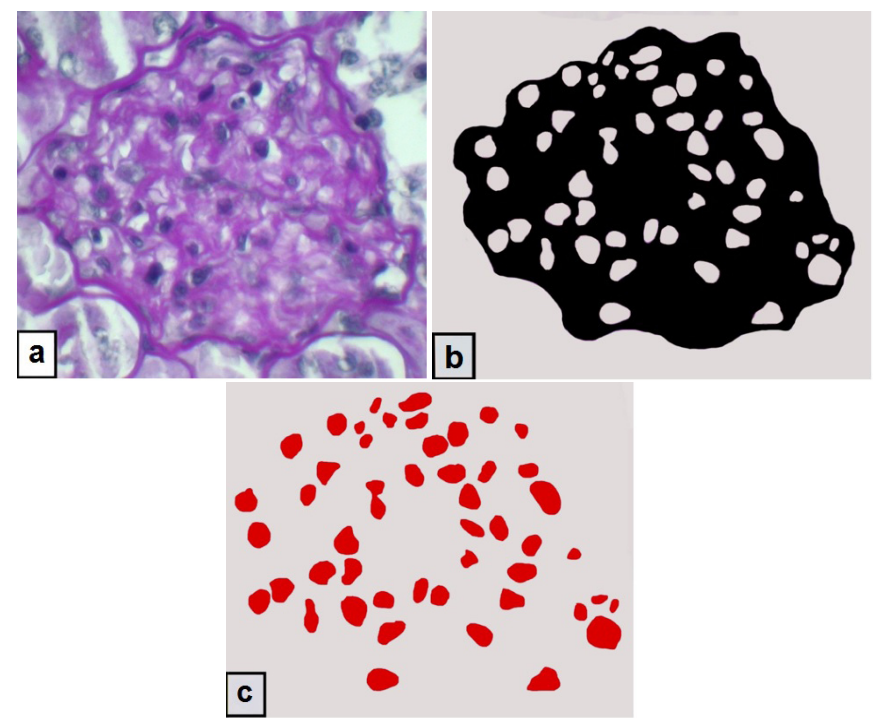

Fig. 1. Computer analysis of the mesangium area and glomerular capillaries after 8 months of STZ-induced DM: 1a-kidney glomerulus; $1 b$ - mesangium area is significantly enlarged; $1 c$ - reduction of the glomerular capillary lumen area. Staining with Schiff reagent according to McManus; x1200.

The canal lumens were expanded; the basal membranes of the canals were thickened. Nephrocytes were in a state of hyalinedrop dystrophy. The blood vessels were full-blooded. The walls of the arteries were thickened; the elastic membranes were hyperplastic. The veins were full-blooded. Finally, among the massive expansion of connective tissue, it was almost impossible to differentiate podocytes.

Table 1.

Indicators of renal function in STZ-induced diabetic rats

\begin{tabular}{|l|c|c|c|c|c|c|}
\hline \multicolumn{1}{|c|}{ Group } & $\begin{array}{c}\text { Diuresis } \\
(\mathrm{ml} / \text { day })\end{array}$ & $\begin{array}{c}\text { Urine glucose } \\
\text { concentration } \\
(\mathrm{mmol} / \mathrm{L})\end{array}$ & $\begin{array}{c}\text { Urinary glucose } \\
\text { excretion } \\
(\mu \mathrm{mol} / \mathrm{day})\end{array}$ & $\begin{array}{c}\text { Urine protein } \\
\text { concentration } \\
(\mathrm{mg} / \mathrm{ml})\end{array}$ & $\begin{array}{c}\text { Urinary protein } \\
\text { excretion } \\
(\mathrm{mg} / \mathrm{day})\end{array}$ & $\begin{array}{c}\text { Urinary creatinine } \\
\text { excretion } \\
(\mu \mathrm{mol} / \mathrm{day})\end{array}$ \\
\hline $\begin{array}{l}\text { After 1 month of } \\
\text { STZ-induced DM }\end{array}$ & $8.0(7.0 ; 16.4)$ & $0.7(0.5 ; 9.5)$ & $8.7(4.7 ; 20.9)$ & $2.0(1.5 ; 2.8)$ & $18.0(13.3 ; 31.2)$ & $64.0(45.9 ; 113.1)$ \\
\hline P-value & $P>0.05$ & $P=0.0000$ & $P=0.0000$ & - & $P=0.002$ & $P=0.0000$ \\
\hline $\begin{array}{l}\text { After 8 months of } \\
\text { STZ-induced DM }\end{array}$ & $5.7(3.6 ; 9.0)$ & $1.9(1.8 ; 2.6)$ & $14.8(9.1 ; 20.0)$ & $2.0(0.9 ; 2.8)$ & $8.7(6.6 ; 12.6)$ & $59.9(42.6 ; 78.3)$ \\
\hline
\end{tabular}


Table 2.

Indicators of FRO process activity in the kidneys of STZ-induced diabetic rats

\begin{tabular}{|l|c|c|c|c|c|c|}
\hline \multicolumn{1}{|c|}{ Group } & $\begin{array}{c}\text { TBARP } \\
(\mu \mathrm{mol} / \mathrm{mg})\end{array}$ & $\begin{array}{c}\text { TPA } \\
(\%)\end{array}$ & $\begin{array}{c}\text { TAA } \\
(\%)\end{array}$ & $\begin{array}{c}\text { GPx } \\
(\%)\end{array}$ & $\begin{array}{c}\text { CAT } \\
(\%)\end{array}$ & $\begin{array}{c}\text { SOD } \\
(\%)\end{array}$ \\
\hline $\begin{array}{l}\text { After 1 month of } \\
\text { STZ-induced DM }\end{array}$ & $8.5(8.5 ; 8.8)$ & $70.7(68.6 ; 71.2)$ & $46.3(43.6 ; 46.9)$ & $45.3(42.1 ; 47.8)$ & $10.3(6.8 ; 13.0)$ & $23.1(18.4 ; 26.0)$ \\
\hline$P$-value & $P>0.05$ & $P=0.0001$ & $P=0.0001$ & $P=0.0000$ & $P>0.05$ & $P=0.014$ \\
\hline $\begin{array}{l}\text { After 8 months of } \\
\text { STZ-induced DM }\end{array}$ & $6.6(6.0 ; 7.0)$ & $28.4(24.1 ; 32.6)$ & $11.3(8.9 ; 14.8)$ & $55.1(50.7 ; 63.1)$ & $12.9(8.7 ; 16.9$ & $11.3(9.2 ; 15.6)$ \\
\hline
\end{tabular}

Table 3.

Morphological characteristics of rat kidneys in STZ-induced DM and in normal conditions

\begin{tabular}{|l|c|c|c|c|}
\hline \multicolumn{1}{|c|}{ Parameter } & $\begin{array}{c}\text { Norm } \\
(1)\end{array}$ & $\begin{array}{c}\text { After 1 month of } \\
\text { STZ-induced DM } \\
(2)\end{array}$ & $\begin{array}{c}\text { After 8 months of } \\
\text { STZ-induced DM } \\
(3)\end{array}$ & $P$-value $(<0.05)$ \\
\hline $\begin{array}{l}\text { Area of kidney glomeruli } \\
\left(\mu \mathrm{m}^{2}\right)\end{array}$ & $6174.7 \pm 257.5$ & $7918.9 \pm 367.5$ & $8174.9 \pm 310.6$ & $\begin{array}{c}P_{1-2}=0.002 \\
P_{1-3}=0.0003\end{array}$ \\
\hline $\begin{array}{l}\text { Total area of vessels in glomerulus } \\
\left(\mu \mathrm{m}^{2}\right)\end{array}$ & $2900 \pm 27.4$ & $1825.4 \pm 25.3$ & $1083.0 \pm 57.8$ & $\begin{array}{l}P_{1-2}=0.0000 \\
P_{1-3}=0.0000\end{array}$ \\
\hline $\begin{array}{l}\text { Glomerular capillary lumen area } \\
\left(\mu \mathrm{m}^{2}\right)\end{array}$ & $47.5 \pm 3.7$ & $42.8 \pm 4.3$ & $22.2 \pm 1.5$ & $\begin{array}{l}P_{2-3}=0.0000 \\
P_{1-3}^{2-3}=0.00000\end{array}$ \\
\hline $\begin{array}{l}\text { Mesangium area of glomeruli } \\
\left(\mu \mathrm{m}^{2}\right)\end{array}$ & $4738.7 \pm 43.3$ & $6849.2 \pm 45.5$ & $7090.3 \pm 577.3$ & $\begin{array}{l}P_{1-2}=0.0000 \\
P_{1-3}=0.0000\end{array}$ \\
\hline $\begin{array}{l}\text { Podocytes } \\
(\text { number })\end{array}$ & $10.2 \pm 0.20$ & $4.9 \pm 0.40$ & Not detected & $P_{1-2}=0.0000$ \\
\hline
\end{tabular}

\section{Discussion}

Summarizing the above-mentioned data, we found a clear picture of the DN progression in the 8-month STZinduced diabetic rats in comparison with the 1-month STZinduced diabetic rats. Analysis of biochemical markers of DN showed that with 8-month DM, an increase in glucose concentration in urine and renal excretion level occurred as expected in comparison with 1 month of the disease.

In addition, the results of determining the parameters of oxidative damage to the renal tissue of the 8-month STZinduced diabetic rats were noted. There was a pronounced decrease in the value of integrative indicators: TPA and TAA, as well as a twofold decrease in the SOD activity. In our opinion, this testified to the depletion of protective biochemical resources of the kidneys against the background of prolonged oxidative stress caused by large glycosuria.

Finally, there was clear morphological evidence of DN progression. First, this is shown by an almost double decrease in the total area of vessels in the glomerulus and the area of glomerulus capillary lumen relative to 1 month of DM. At the same time, it should be noted that the area of glomerulus capillary lumen did not differ from the norm after 1 month of STZ-induced DM. Attention is also drawn to the fact that the histological methods used failed to verify podocytes in the kidney glomerulus. According to modern ideas, the violation of the structure and function of these cells plays a decisive role in the DN development. ${ }^{(11,12)}$ It is possible that the recorded phenomenon most clearly indicates a severe course of chronic 8-month DN, which seems to be already irreversible during this period and is not subject to drug therapy.

\section{Conclusion}

Thus, DN in the 8-month STZ-induced DM is more pronounced than with the 1-month STZ-induced DM. The revealed biochemical and morphological signs of the 8-month STZ-induced DM indicate the irreversible nature of its course and the impossibility of its pharmacological correction.

\section{Competing Interests} interests.

The authors declare that they have no competing

\section{References}

1. Iminger-Finger I, Kargul J, Laurent GJ. Diabetes: Present and future. Int J Biochem Cell Biol. 2017 Jul;88:196. doi: 10.1016/j.biocel.2017.06.003. 
2. Fouli GE, Gnudi L. The Future: Experimental Therapies for Renal Disease in Diabetes. Nephron. 2019;143(1):3-7. doi: $10.1159 / 000492825$.

3. Zharikov AYu, Shchekochikhina RO. [Diabetic Nephropaty. Modern View of The Problem]. Bulletin of Medical Science. 2018;2(10):22-28. [Article in Russian].

4. Van JA, Scholey JW, Konvalinka A. Insights into Diabetic Kidney Disease Using Urinary Proteomics and Bioinformatics. J Am Soc Nephrol. 2017;28(4):1050-1061 doi: 10.1681/ ASN.2016091018.

5. Kiliś-Pstrusińska K. [Carnosine, carnosinase and kidney diseases]. Postepy Hig Med Dosw (Online) 2012;66:215-21. [Article in Polish].

6. Peters V, Klessens CQ, Baelde HJ, Singler B, Veraar KA, et al. Intrinsic carnosine metabolism in the human kidney. Amino Acids. 2015;47(12):2541-50. doi: 10.1007/s00726-015-2045-7. 7. Filinova SO, Zharikov AY, Bobrov IP, Mazko ON, Makarova OG. [Pathomorphological picture of diabetic nephropathy in experimental diabetes mellitus]. Kazan Medical Journal 2019;100(1):147-152. [Article in Russian].

8. Zharikov AYu, Balandovich BA, Shchekochikhina RO, Zharikova GV. Kidney function in experimental diabetes. Nephrology. 2019;23(1):79-83.

9. Spasov AA, Vorohkova MP, Snegur GL, Cheplyaeva NI, Chepurnova MV. [Experimental model of a type 2 diabetes]. Biomedicine 2011;(3):12-18. [Article in Russian].

10. Bryukhanov VM, Zverev YaF, Lampatov VV, Zharikov $\mathrm{AYu}$, Talalayeva OS. Methods of preclinical (experimental) research of the effect of medicines on renal function. Novosibirsk: Geo; 2013. [In Russian].

11. Fiorina P, Vergani A, Bassi R, Niewczas MA, Altintas MM, Pezzolesi MG, et al. Role of podocyte B7-1 in diabetic nephropathy. J Am Soc Nephrol. 2014;25(7):1415-29. doi: 10.1681/ASN.2013050518.

12. Kim NH. Podocyte hypertrophy in diabetic nephropathy. Nephrology (Carlton). 2005;10 Suppl:S14-6. 